\title{
New sources of soybean seed meal and oil composition traits identified through TILLING Emily C Dierking ${ }^{1}$ and Kristin D Bilyeu*1,2
}

Address: ${ }^{1}$ University of Missouri-Columbia, Division of Plant Sciences, 110 Waters Hall, Columbia, MO 65211, USA and ${ }^{2}$ USDA-ARS, Plant Genetics Research Unit, 110 Waters Hall, Columbia, MO 65211, USA

Email: Emily C Dierking -Emily.Dierking@mizzou.edu; Kristin D Bilyeu* - bilyeuk@missouri.edu

* Corresponding author

Published: 14 July 2009

BMC Plant Biology 2009, 9:89 doi:10.1186/1471-2229-9-89
Received: 24 April 2009

Accepted: 14 July 2009

This article is available from: http://www.biomedcentral.com/I47I-2229/9/89

(c) 2009 Dierking and Bilyeu; licensee BioMed Central Ltd.

This is an Open Access article distributed under the terms of the Creative Commons Attribution License (http://creativecommons.org/licenses/by/2.0), which permits unrestricted use, distribution, and reproduction in any medium, provided the original work is properly cited.

\begin{abstract}
Background: Several techniques are available to study gene function, but many are less than ideal for soybean. Reverse genetics, a relatively new approach, can be utilized to identify novel mutations in candidate genes; this technique has not produced an allelic variant with a confirmed phenotype in soybean. Soybean raffinose synthase genes and microsomal omega- 6 fatty acid desaturase genes were screened for novel alleles in mutagenized soybean populations.
\end{abstract}

Results: Four mutations in independent lines were identified in the raffinose synthase gene RS2; two mutations resulted in amino acid mutations and one resulted in an altered seed oligosaccharide phenotype. The resulting phenotype was an increase in seed sucrose levels as well as a decrease in both raffinose and stachyose seed oligosaccharide levels. Three mutations in independent lines were identified in the omega- 6 fatty acid desaturase gene FAD2-IA; all three mutations resulted in missense amino acid mutations and one resulted in an altered seed fatty acid profile that led to an increase in oleic acid and a decrease in linoleic acid in the seed oil.

Conclusion: The oligosaccharide phenotype controlled by the novel RS2 allele is similar to previously observed seed oligosaccharide phenotypes in RS2 mutant (PI 200508) allele-containing lines. Due to the anti-nutritional characteristics of raffinose and stachyose, this represents a positive change in seed composition. The fatty acid phenotype controlled by the novel FAD2-IA allele controls an increase in oleic acid in the seed oil, a phenotype also observed in a line previously characterized to have a null allele of the FAD2-IA gene. Molecular marker assays were developed to reliably detect the inheritance of the mutant alleles and can be used in efficient breeding for these desired seed phenotypes. Our results serve as the first demonstration of the identification of soybean mutants controlling seed phenotypes discovered through the reverse genetics technique TILLING.

\section{Background}

Reverse genetics is potentially a powerful strategy used to identify novel, induced mutations in candidate genes. Utilizing reverse genetics allows us to take advantage of genes characterized in other plant genomes and use this knowl- edge to create a pool of candidate genes in soybean which can then be screened for genotypic variants. The function of the gene is further characterized by identifying predicted mutant phenotypes. Alternatively this technique can be applied to genes with known function to create an 
allelic series to avoid possible lethality issues in genes essential for plant growth or development. The recent release of the soybean genome sequence is an especially valuable asset for soybean reverse genetics.

Targeting Induced Local Lesions IN Genomes (TILLING) is a reverse genetics technique that serves as a high throughput method to identify unique, chemically induced mutations within target genes which have potential to change gene expression and/or function [1-3]. We developed two soybean TILLING populations utilizing the chemical mutagen ethyl-methanesulfonate (EMS) as part of an effort to provide a resource to identify novel alleles of genes with a role in soybean seed composition traits [4]. Chemical mutagenesis, either EMS or NMU (Nnitroso-N-methylurea) typically induces single nucleotide polymorphisms; these point mutations are extremely useful both for studying gene function as well as for their potential use in crop improvement [4]. The mutants are generally characterized by knocked-down or altered gene function rather than a knock-out; for the populations used in this study, the previously characterized mutation distributions were 45 or $33 \%$ missense, 51 or $58 \%$ silent, and 4 or $8 \%$ truncation [4].

Previously, a number of techniques which were first proven in other crops have been applied to soybean functional genomics studies, but each strategy has obstacles in terms of efficiency, directness, timing, and regulatory issues. Transformation of soybean with either Agrobacterium tumefaciens or $A$. rhizogenes has been effective in studying gene function, although it is not very efficient [5] and can be limited by genotype specificity [6]. Directed cosuppression, overexpression of genes, and RNAi have all been utilized to gain insights into gene function and produce desired phenotypes in transgenic soybeans [7-10]. While the use of transgenic technology is suitable for traits that can be utilized broadly for commodity soybeans, the current regulatory environment is prohibitive to extensive use of transgenic technology for many individual soybean traits.

The more traditional forward genetics approach relies on the identification of a mutant phenotype followed by the investigation of the causative gene. Forward genetics screening has historically been a very valuable strategy to identify different sources of soybean traits. However, screening divergent germplasm or induced mutant populations may fail to deliver the desired phenotype when multiple genes are involved. In soybean, the genome functions as diploid, but it has undergone rounds of genome duplication that often results in functional genetic redundancy [11-15].

The objective of this work was to take advantage of the availability of soybean candidate genes that were known to control seed composition traits as targets for the TILLING reverse genetics strategy; the goal was to identify novel mutant alleles that could be characterized for desirable seed phenotypes. Our targets were a raffinose synthase (EC 2.4.1.82) and an omega-6 fatty acid desaturase (EC 1.3.1.35) controlling seed oligosaccharide levels and oleic acid levels in the seed oil, respectively.

Raffinose synthase catalyzes the biochemical reaction to produce raffinose from sucrose and galactinol. Stachyose is formed in a stepwise reaction utilizing raffinose and galactinol as substrates. Both raffinose and stachyose are indigestible by monogastric animals and are therefore considered anti-nutritional components of soybean meal. Previously, the PI 200508 allele of RS2 was associated with the increased sucrose and low raffinose and stachyose seed phenotype [16].

In addition to the targeted raffinose synthase candidate gene, we screened for novel mutant alleles of the soybean seed-expressed omega- 6 fatty acid desaturase gene FAD2$1 \mathrm{~A}$. This fatty acid desaturase catalyzes the conversion of oleic acid precursors into linoleic acid precursors that accumulate in the seed oil $[17,18]$. Mutations in FAD2-1A have been recovered previously using a forward genetics strategy, and result in an increase in oleic acid levels and a decrease in linoleic acid levels, a phenotype desirable for cooking and industrial oils. The elevated oleic acid soybean line M23 was induced by X-ray mutagenesis and has been shown to have a genomic deletion that includes the FAD2-1A gene; a second elevated oleic acid soybean line contained a single base deletion in the FAD2-1A gene $[18,19]$. Cooking oil is in demand that contains elevated oleic acid and decreased linolenic acid. Although the genetic combining ability for mutant alleles of the FAD2$1 \mathrm{~A}$ gene and microsomal omega- 3 fatty acid desaturase (FAD3) genes has been reported, the exact relationship between increased oleic acid levels and decreased linolenic acid levels has not been clearly defined $[[20,21] \mathrm{K}$. Bilyeu, unpublished]. The oleic acid level in soybean seed oil has been demonstrated to be very sensitive to the environment [22], which has complicated the identification and analysis of elevated oleic acid soybean lines.

\section{Results \\ Identification of soybean raffinose synthase (RS2) mutant alleles}

Previously, mutations in the soybean raffinose synthase gene, RS2, have been shown to result in an increase in seed sucrose and a decrease in raffinose and stachyose [16]. Reverse genetics screening of the EMS mutagenized populations created the potential to find additional mutations in RS2 and confirm the contribution of this gene to the seed oligosaccharide phenotype in soybean. A portion of the RS2 gene [GenBank: EU651888] was screened for mutations utilizing the TILLING strategy [4]; four lines 
were identified which contained single nucleotide polymorphisms (SNPs). These lines were subsequently confirmed by sequence analysis to contain independent RS2 mutations. The four identified lines all contained a SNP typical of EMS mutagenesis, G/C to A/T transitions. Two of the mutations did not result in amino acid changes and therefore were not considered candidates for phenotypic characterization. The other two lines, designated 165 and 397, contained mutations which resulted in missense amino acid changes (Figure 1)[23].
DNA from $\mathrm{M}_{2}$ tissue of line 165 contained a homozygous SNP (c448t in the coding sequence) resulting in S150F amino acid change. DNA from $\mathrm{M}_{2}$ tissue of line 397 contained a heterozygous SNP (c319t in the coding sequence) resulting in a T107I amino acid change. The induced mutations in both line 165 and 397 lie in semi-conserved regions of plant raffinose synthase gene sequences (Figure 1). $M_{3}$ seedlings from lines 165 and 397 were characterized for the RS2 alleles, and the homozygous and segre-

A.

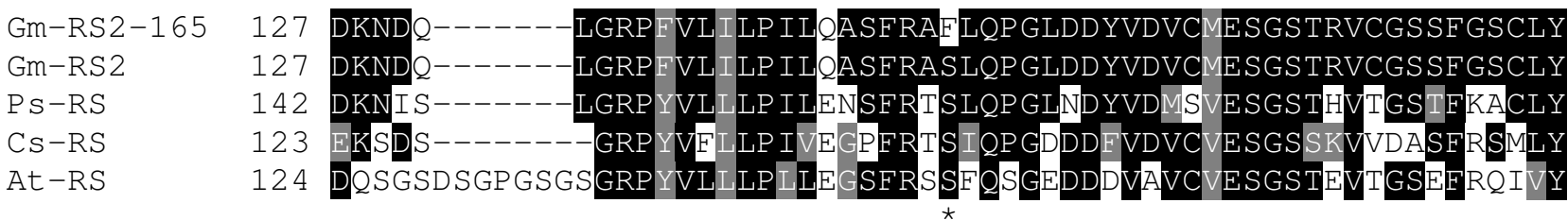

B.

$\begin{array}{lll}\text { Gm-RS2-397 } & 78 & \text {-EPRSRHVASLGKLRGIKFMS IFRFKVWWTIHWVGSNGHELEHETQMMLLDKNDQ------ } \\ \text { Gm-RS2 } & 78 & \text {-EPRSRHVASLGKLRGIKFMS IFRFKVWWTTHWVGSNGHELEHETQMMLLDKNDQ------ } \\ \text { PS-RS } & 93 & \text {-EAKSHHVVPLGKLKGIKFTS IFRFKVWWTTHWVGTNGHELQHETQILILDKNIS------ } \\ \text { CS-RS } & 74 & \text {-EPDSRHVVSIGKLKDIRFMS IFRFKVWWTTHWVGRNGGDLESETQIVILEKSDS------ } \\ \text { At-RS } & 74 \text { GEPKSHHVASIGKLKNIRFMS IFRFKVWWTTHWVGSNGRDIENETQIIILDQSGSDSGP GS }\end{array}$

C.

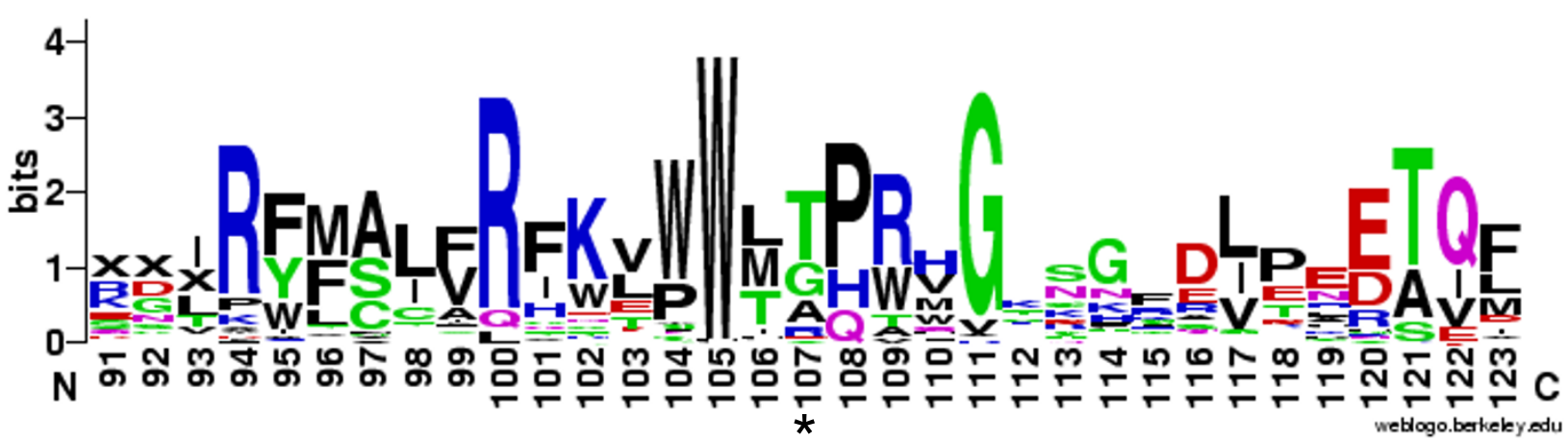

\section{Figure I}

Raffinose synthase amino acid sequence alignments in the regions surrounding the induced mutations in the RS2 gene. Amino acid positions are indicated at the beginning of each alignment. The position of the polymorphic amino acid is indicated by an asterisk. Identical amino acid residues are highlighted in black while similar amino acid residues are highlighted in gray. A. The exon one region containing the induced mutation in line 165 which resulted in SI50F. B. The exon one region containing the induced mutation in line 397 which resulted in TI07I. C. Weblogo output of the amino acid conservation of raffinose synthase enzymes aligned as part of the BLINK feature at NCBI http://www.ncbi.nlm.nih.gov/staff/tao/URLAPI/ BLINK tut2.html using GI number 1876I04/4. Amino acid positions within the protein are listed on the $X$ axis. The overall height for each amino acid column stack indicates the sequence conservation at that position while the height of one-letter amino acid symbols within the column stack indicates the relative frequency of each amino acid in that position [23]. 
gating nature of the identified mutant alleles was confirmed, respectively.

\section{Identification of omega-6 fatty acid desaturase FAD2-IA mutant alleles}

Mutations in the soybean omega- 6 fatty acid desaturase gene FAD2-1A have been shown to elevate oleic acid content of the seed oil $[18,19]$. Therefore, one of our main targets was to identify variant alleles of the FAD2-1A gene present in the TILLING populations. Primers were designed to specifically amplify and interrogate the FAD2$1 \mathrm{~A}$ sequences present in the mutant populations, and three individual lines were identified; these lines were subsequently confirmed by sequence analysis to contain independent FAD2-1A mutations.

The FAD2-1A mutations identified in DNA from $\mathrm{M}_{2}$ tissue were homozygous in all three cases, and the mutations were confirmed in the $\mathrm{M}_{3}$ seedlings corresponding to the original $\mathrm{M}_{2}$ plants. Line 17D contained a SNP (g350a in the coding sequence) resulting in the amino acid change S117N. Line 615 contained a SNP (c713t in the coding sequence) resulting in the amino acid change S238F. Line 743 contained a SNP (g1121a in the coding sequence) resulting in the amino acid change G374E. The missense mutation for line 17D was in a highly conserved region of the protein sequence, while the missense mutations in lines 615 and 743 were in less conserved regions (Figure 2)[24].

\section{Oligosaccharide content phenotype of RS2 induced mutants}

Seeds from the homozygous S150F line 165 did not have an obvious oligosaccharide phenotype as determined by quantitatively measuring sucrose, raffinose and stachyose of $\mathrm{M}_{3}$ seeds and comparing them to wild-type seeds (data not shown). However, the line 397 harboring the T107I $R S 2$ allele displayed a phenotype predicted for mutations in the soybean raffinose synthase gene RS2.

Taking advantage of the heterozygous state of the induced mutation in line 397, we investigated the inheritance of this novel allele and its subsequent effect on seed oligosaccharide content by screening thirty-seven individual $\mathrm{M}_{3}$ seeds for both oligosaccharide phenotype and RS2 genotype (Figure 3). Seeds were chipped into two approximately equal pieces, one was used for single seed oligosaccharide phenotype analysis and the remaining portion containing the embryo was germinated and genotyped by the developed allele specific molecular marker assay. The genotype/phenotype association results on $\mathrm{M}_{3}$ seeds reveal an increase in sucrose along with decreases in raffinose and stachyose content when seeds were homozygous for the mutant RS2 allele (Figure 3). Furthermore, one wild-type allele of RS2 was sufficient to pro- duce the wild-type oligosaccharide seed phenotype, which is consistent with previous results (Figure 3) [16].

A population consisting of plants with contrasting RS2 genotypes was then developed from line 397-derived plants that contained either homozygous wild-type (Williams 82) or homozygous mutant alleles at the RS2 locus in order to further characterize the phenotype resulting from the novel allele. Seven independent wild-type RS2 and nine independent mutant $R S 2$ plants were selected to negate the action of unidentified genes that may contribute to the oligosaccharide content; the mutation density was previously determined to average $1 / 550$ kilobases [4]. Four seeds from each of the plants of the homozygous population were analyzed for oligosaccharide content. For the plants that contained the T107I RS2 mutation, the average seed sucrose was increased by $28 \%$, raffinose was reduced to $37 \%$ and stachyose was reduced to approximately $24 \%$ of 397 -derived seeds which carried the wildtype allele of RS2 (Figure 4). This oligosaccharide phenotype is similar to the phenotype controlled by the previously described RS2 mutant alleles in PI 200508 which also resulted in a decrease in seed raffinose and stachyose content along with an increase in seed sucrose levels [16].

In all cases where RS2 was homozygous mutant, a statistically significant difference in the ratio of sucrose to the sum of raffinose and stachyose was observed when compared to seeds with either RS2 homozygous wild-type or heterozygous alleles. The absolute ratios observed in the homozygous classes were significantly different between the segregating seed samples (Figure 3) and the homozygous plants analyzed (Figure 4); a higher mean ratio was observed for the field grown seeds compared to the seeds produced in the growth chamber.

\section{Fatty acid phenotype of FAD2-IA mutants}

The expected phenotype for soybeans containing mutations in FAD2-1A is an increase in the oleic acid content of the seed oil with a concomitant decrease in linoleic acid. Since the mutant lines were homozygous for the mutations, all three lines were grown two years in a field environment along with lines that contained wild-type or mutant alleles of FAD2-1A, FAD3A and FAD3C to produce seeds for fatty acid analysis. Lines 615 and 743 did not produce significantly different oleic acid levels from the progenitor line 'Williams $82^{\prime}$ [25] and were only grown in 2007 (data not shown). Oleic acid levels for line 17D containing homozygous FAD2-1A S117N mutant alleles were significantly higher than those for Williams 82 (Figure 5). The mean oleic acid level for the seeds containing homozygous FAD2-1A 17D mutant alleles was lower than the mean oleic acid level for two independent lines which possess a null FAD2-1A allele (KB05-7 and M23, Figure 5). The results were similar for the experiments performed in 2007 and 2008, although there was a 
A.

$\begin{array}{lll}\text { FAD2-1a17D } & 87 & \text { LIAWP IYWVLQGCLLTGVWVIAHECGHHAFNKYQWVDDVVGLTLHSTLLVPYFSWKISHR } \\ \text { GmFAD2-1A } & 87 & \text { LIAWP IYWVLQGCLLTGVWVIAHECGHHAFSKYQWVDDVVGLTLHSTLLVPYFSWKISHR } \\ \text { GmFAD2-1B } & 87 & \text { LIAWP IYWVLQGCILTGVWVIAHECGHHAFSKYPWVDDVMGLTVHSALLVPYF SWKISHR } \\ \text { GmFAD2-2A } & 82 & \text { FVAWP IYWAVQGCILTGVWVIAHECGHHAFSDYQLLDDIVGLILHSALLVPYF SWKYSHR } \\ \text { GmFAD2-2B } & 82 & \text { FVAWP IYWAVQVCILTGVWVIAHECGHHAFSDYQLLDDIVGLILHSALLVPYF SWKYSHR } \\ \text { AtFAD2 } & 82 & \text { YLAWP LYWACQGCVLTGIWVIAHECGHHAFSDYQWLDDTVGLIFHSFLLVPYF SWKYSHR }\end{array}$

B. GmFAD2-1A 208

GmFAD2-1B 208

GmFAD2-2A 204

GmFAD2-2B 204

AtFAD2

204 DGFACHFFPNAP IYNDR

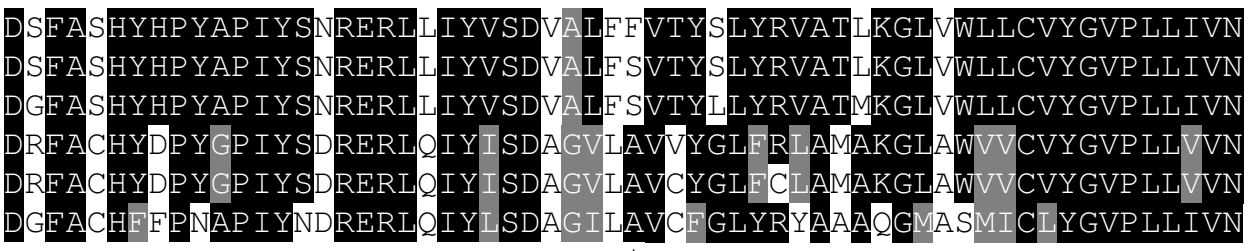

C.

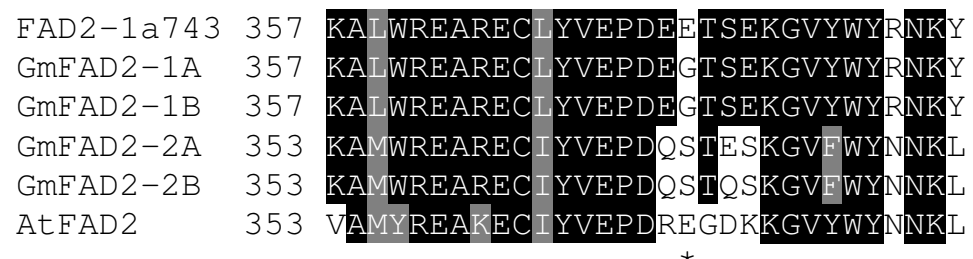

AtFAD2

353 VAMYREAKECIYVEPDRE

D.

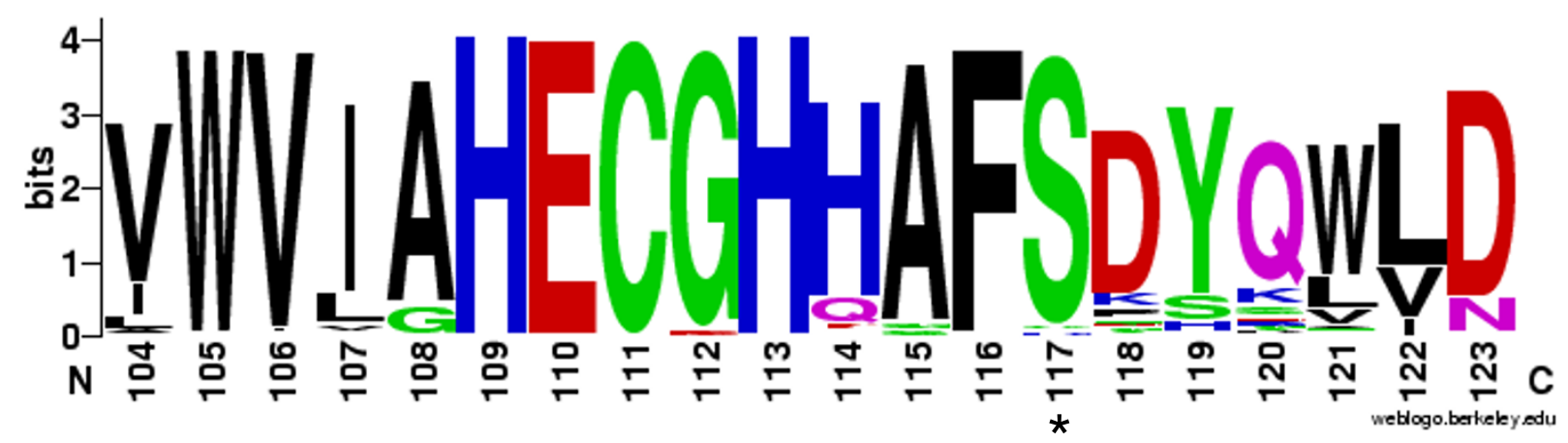

Figure 2

Omega-6 fatty acid desaturase (FAD2) amino acid sequence alignments in the regions surrounding the induced mutations in the soybean FAD2-I A gene. Amino acid positions are indicated at the beginning of each alignment. The position of the polymorphic amino acid is indicated by an asterisk. Identical amino acid residues are highlighted in black while similar amino acid residues are highlighted in gray. Underlined amino acids represent the histidine-rich region la, a critical region for fatty acid desaturase enzyme function [24]. A. The region containing the induced mutation in line I7D which resulted in SII7N. B. The region containing the induced mutation in line 615 which resulted in S238F. C. The region containing the induced mutation in line 743 which resulted in G374E. D. Weblogo output of the amino acid conservation in region la of omega-6 fatty acid desaturase enzymes [24] aligned as part of the BLINK feature at NCBI using GI number I97। I I 724. 


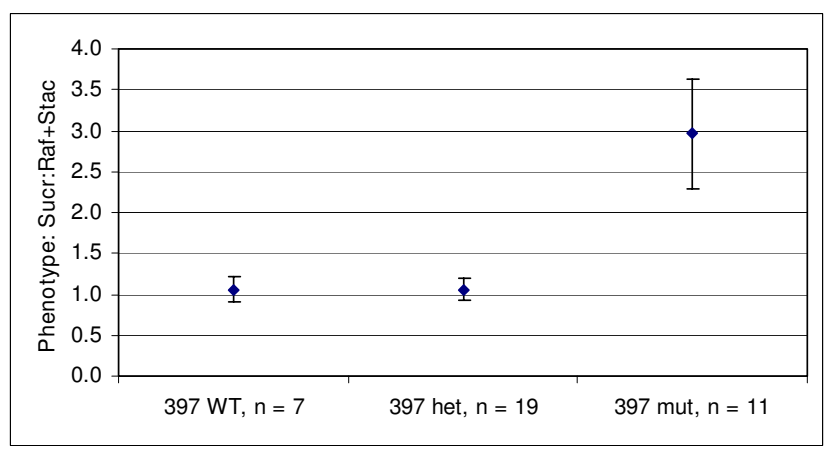

Figure 3

Phenotype to genotype association of segregating $M_{3}$ seeds from line 397 . The $x$-axis is represented by the three distinct RS2 genotypes: WT represents wild-type RS2 alleles, mut represents mutant, and het represents heterozygous RS2 alleles from the line 397 ; $\mathrm{n}$ is the number of individual seeds for each class. The oligosaccharide phenotype of 37 individual $M_{3}$ seeds was determined. The data represents the mean of the ratio of extractable seed sucrose to the sum of raffinose and stachyose. Error bars represent plus and minus one standard deviation from the mean.

trend for higher oleic acid levels in 2008 for the lines containing FAD2-1A mutations.

The inheritance of the $\mathrm{S} 117 \mathrm{~N}$ mutant FAD2-1A allele from line $17 \mathrm{D}$ and the fatty acid phenotype was evaluated in selected homozygous progeny derived from a cross of

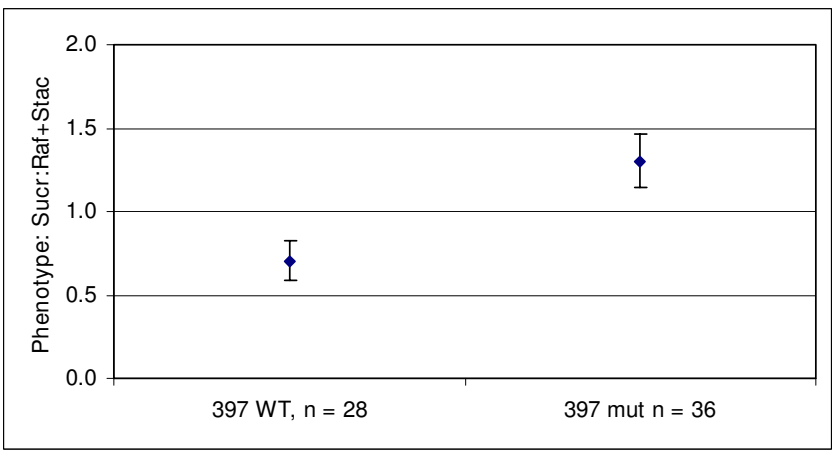

\section{Figure 4}

Phenotype to genotype association of a homozygous soybean population derived from the mutagenized soybean line 397 . The $x$-axis is represented by two distinct RS2 genotypes: WT represents wild-type RS2 alleles and mut represents mutant $R S 2$ alleles from the line 397; $\mathrm{n}$ represents the number of individual seeds from each genotypic class. The oligosaccharide phenotype of four individual $M_{4}$ seeds from each plant was determined. The data represents the mean of the ratio of extractable seed sucrose to the sum of raffinose and stachyose. Error bars represent plus and minus one standard deviation from the mean.
Williams 82 with line 17D. Molecular marker assays specific for the $S 117 \mathrm{~N}$ mutant FAD2-1A allele from 17D were designed and validated. Six independent $F_{3}$ plants homozygous for the 17D mutant alleles and five independent homozygous wild-type plants were grown to produce seed in a field environment. Fatty acid analysis on the resulting $\mathrm{F}_{4}$ seeds demonstrated significantly higher mean oleic acid levels for those seeds which were homozygous for the mutant $\mathrm{S} 117 \mathrm{~N}$ allele of FAD2-1A (Figure 6). The mean linoleic acid level for the FAD2-1A mutant seeds was significantly lower than the wild-type FAD2-1A seeds. Overall, the significant change in oleic acid content and the concomitant decrease in linoleic acid content is consistent with the $\mathrm{S} 117 \mathrm{~N}$ alleles of FAD2-1A responsible for disrupting at least part of the seed expressed omega- 6 fatty acid desaturase enzymatic capacity.

\section{Discussion}

Here we demonstrate the utility of the TILLING reverse genetics strategy in identifying novel soybean lines containing desirable seed traits. The targeted raffinose synthase and omega- 6 fatty acid desaturase genes were chosen based on previous research revealing their involvement in seed oligosaccharide content and oleic acid levels, respectively. For both genes, multiple variant alleles were identified, and one line containing mutant alleles of each of the genes produced the predicted phenotype. The phenotypes were confirmed to be dependent on the inheritance of the mutant alleles. Because the roles of the candidate genes were confirmed, the developed molecular marker assays enable direct selection for the mutant allele in the heterozygous state, when the phenotype would not otherwise be apparent. Seed mutagenesis and reverse genetics are not transgenic technologies, so soybean varieties that incorporate mutant alleles identified by TILLING are conventional lines which are not subject to any regulatory restrictions. Soybean traits identified by TILLING can be rapidly incorporated into elite soybean cultivars and released to producers.

The identification of an induced mutation in RS2 serves as an additional confirmation of the contribution of this gene to the seed raffinose and stachyose content [16]. Similar to the PI 200508 mutant allele of RS2, the mutagenized line 397 has reduced raffinose and stachyose as well as an increase in seed sucrose content. Since similar phenotypes resulted from two independent mutations in $R S 2$, it may indicate that the mutations in the gene are deleterious to enzyme function and the detected raffinose in these lines is the result of one or more additional soybean raffinose synthase genes. It appears that inheritance of a single wild-type allele of RS2 is sufficient for a wild-type oligosaccharide seed phenotype, which is consistent with previously characterized RS2 alleles [16]. 


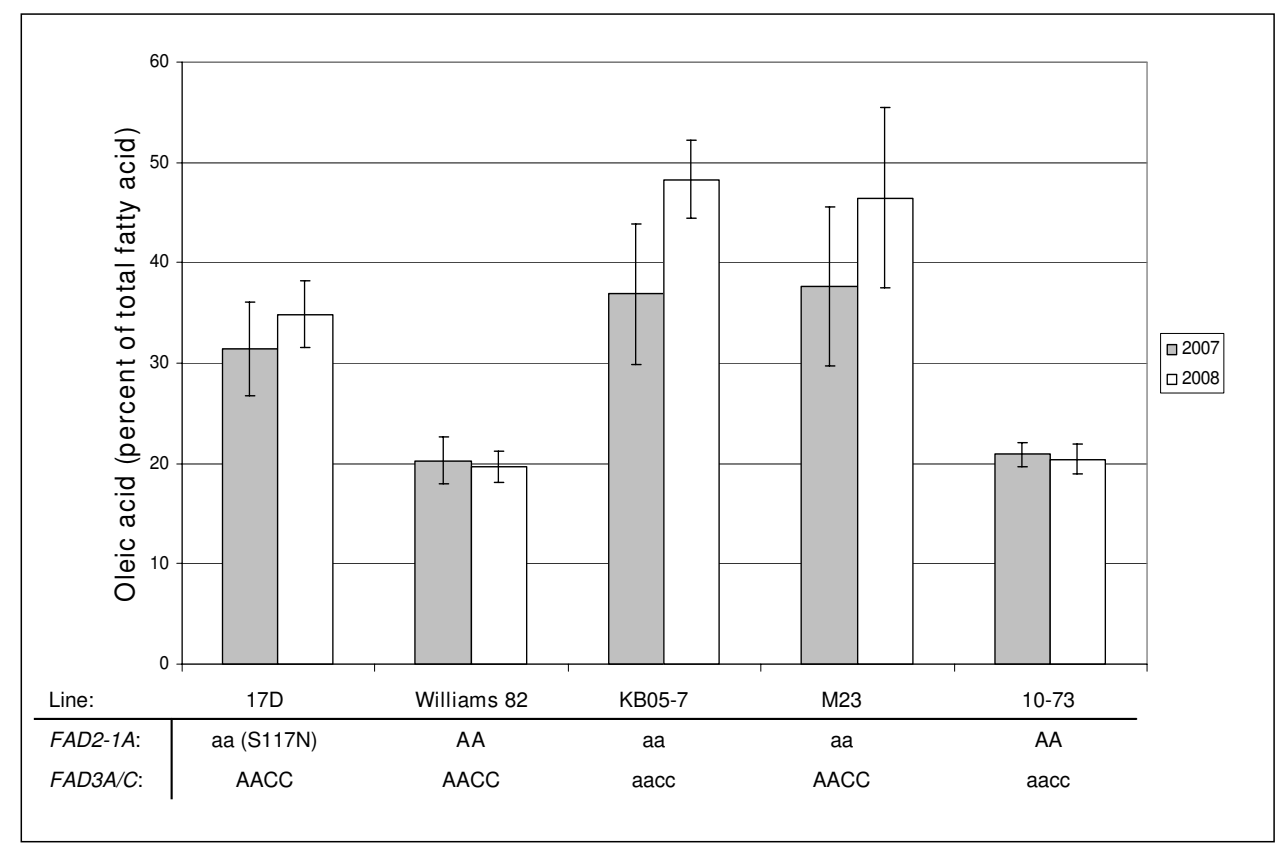

\section{Figure 5}

Increased oleic acid content in soybean mutant FAD2-IA mutant lines compared to FAD2-IA wild-type lines from field produced seeds in two years. Histograms represent the mean oleic acid content as a percentage of the seed oil for 25 individual seed samples representing five plants from each line listed on the $\mathbf{x}$-axis. Error bars represent plus and minus one standard deviation of the mean. For each line, the FAD2-IA, FAD3A, and FAD3C genotypes are listed below the line name; lowercase letters represent the mutant case, and uppercase letters represent the wild-type case. Line I7D is the result of mutagenesis of line Williams 82, and contains an SII 7N missense mutation of FAD2-IA (bolded for comparison); M23 contains a genomic deletion of FAD2-IA [18]; 10-73 contains mutant alleles of FAD3A and FAD3C, which reduce linolenic acid levels but do not affect oleic acid levels [33]; KB05-7 is a derivative of a cross between 10-73 and M23 which combines mutant alleles of FAD2-IA, FAD3A, and FAD3C.

Soybean seed oligosaccharide content appears to be controlled mainly by the RS2 gene. However, both raffinose and stachyose are still present in lines containing RS2 mutants, suggesting that additional raffinose synthase enzyme activity remains during seed development. Other candidate raffinose synthase genes have been identified, but variant alleles have not been confirmed to be associated with altered oligosaccharide content. It is possible that combining an RS2 mutation with variant alleles of other raffinose synthases may reveal epistatic interactions that would otherwise have been masked by a wild-type version of RS2.

The novel $5117 \mathrm{~N}$ allele of $F A D 2-1 \mathrm{~A}$ appears to be deleterious to enzyme function since oleic acid accumulates to significantly higher levels in the seed oil in lines homozygous for the mutation when compared to related lines containing wild-type FAD2-1A. Since the environment has been shown to have an effect on oleic acid content, it was not surprising that the standard deviations were high for oleic acid content for the investigated FAD2$1 \mathrm{~A}$ mutant TILLING line 17D and the FAD2-1A deletion lines M23 and KB05-7 [22]. The observed differences in means with overlapping standard deviations for oleic acid phenotypes and the differences in relative maturity among the TILLING mutant line with the novel FAD2-1A alleles and the FAD2-1A deletion lines M23 and KB05-7 indicates more research will be necessary to clarify the extent of the phenotypic consequences of the FAD2-1A S117N substitution. Nevertheless, this novel FAD2-1A mutant allele provides an additional resource to investigate the agronomic impact of the elevated oleic acid trait in soybeans and an independent confirmation of the contribution of the FAD2-1A gene to oleic acid accumulation in soybean seeds.

Convincing evidence exists that points to genetic redundancy playing a role in oleic acid accumulation. Although the identification of independent FAD2-1A alleles has demonstrated a role for the gene in oleic acid accumulation, the residual omega- 6 fatty acid desaturase activity that allows the production of linoleic and linolenic acids may be encoded by one other closely related gene (FAD2$1 B$ ) which has been shown to be expressed in soybean seeds or the FAD2-2 gene family members members $[11,19,26-28]$. A reverse genetics strategy is particularly 


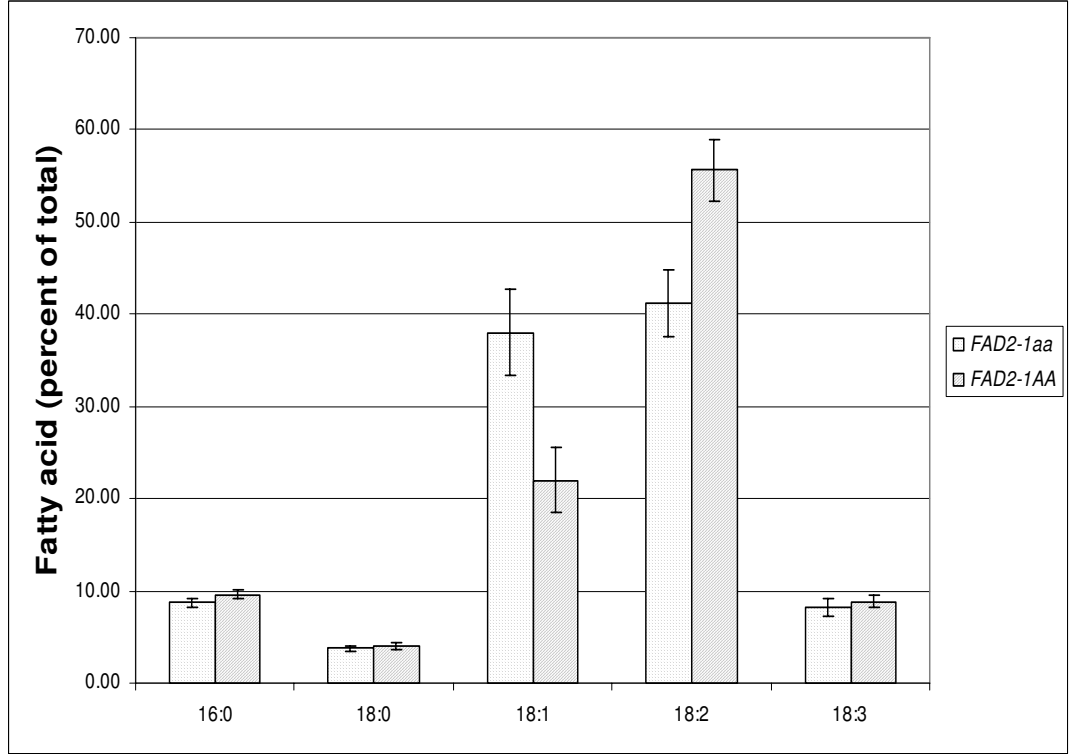

\section{Figure 6}

Inheritance of SI I7N alleles of FAD2-IA results in increased mean oleic acid and decreased linoleic acid soybean seed oil. Soybean lines with contrasting homozygous mutant or wild-type FAD2-IA alleles were developed from a cross of line I7D with Williams 82. Homozygous mutant SI I TN FAD2-IA lines (FAD2-I aa) and homozygous wild-type (FAD2-IAA) lines were grown in the field in 2008. Fatty acid profiles were determined for individual seeds and histograms of mutant (spotted) or wild-type (diagonal lines) represent the mean relative palmitic acid (16:0), stearic acid (I8:0), oleic acid (I 8:I), linoleic acid (I8:2), and linolenic acid (18:3) content of the oil. Error bars represent plus and minus one standard deviation of the mean.

amenable to dissection of desirable phenotypes where genetic redundancy may complicate a forward genetics strategy.

\section{Conclusion}

The use of TILLING to identify novel sources of important soybean seed composition traits confirms the utility of this reverse genetics technology as a route for both gene function analysis and direct applicability for soybean improvement. Soybean now joins wheat, sorghum, pea, and rapeseed as crops that have demonstrated success in identifying traits using TILLING for reverse genetics [2932].

\section{Methods}

\section{Population Development}

The 'Williams 82' [25] EMS mutagenized populations screened in this study were previously described [4]. The populations screened were exposed to 40 or $50 \mathrm{mM}$ EMS. $M_{1}$ plants were advanced to $M_{2}$ families, leaf tissue was collected and DNA prepared from a single $\mathrm{M}_{2}$ plant from each family. $M_{3}$ seeds from each $M_{2}$ plant were catalogued for storage.

\section{Development of RS2 contrasting lines}

Thirty-nine seeds were planted in packets (CYG, Mega International, St. Paul, MN), allowed to germinate, and transferred to soil in flats. Plants were sampled for genotypic determination by allele-specific molecular marker assay described below. A population of only the plants homozygous for either the wild-type or mutant allele of $R S 2$ were transplanted to 3-gallon pots; $1-3$ plants per pot. Seven homozygous wild-type and nine homozygous mutant RS2 $\mathrm{M}_{2: 3}$ plants from the mutagenized line 397 were grown to maturity in a growth chamber with 13 hour day length. The dark temperature was $22^{\circ} \mathrm{C}$ and the light temperature was $28^{\circ} \mathrm{C}$. Plants were grown, three per 3-gallon pot, in PRO-MIX (Premier Horticulture) medium and fertilized with Osmocote Plus (Scotts) per manufacturer's instructions.

\section{Field plant growth}

Plants for seed fatty acid phenotype determination were grown at the Bradford Research and Extension Center (BREC) located near Columbia, $\mathrm{MO}$ in the summer of 2007 and 2008 with irrigation as needed. Williams 82 was the control line since it was the progenitor of line 17D. Several other lines were grown for comparison because of 
their known mutant alleles in the FAD2-1A, FAD3A, and FAD3C genes: M23 contains a deletion of FAD2-1A [18]; $10-73$ contains mutant alleles of FAD3A and FAD3C [33]; KB05-7 is a combination of mutant FAD2-1A, FAD3A, and FAD3C alleles from M23 and 10-73 (K. Bilyeu and J. Shannon, unpublished).

\section{Development of FAD2-I A contrasting lines}

Seeds of a Williams $82 \times 17 \mathrm{D}$ cross were produced at BREC in 2007. The $\mathrm{F}_{1}$ seeds were advanced to $\mathrm{F}_{2}:_{3}$ lines in a Costa Rica winter nursery. Two $\mathrm{F}_{3}$ seeds from each line were germinated and evaluated for their FAD2-1A genotype using the molecular marker assay. Homozygous wild-type or mutant S117N FAD2-1A lines were confirmed by analyzing three additional seedling genotypes from each line. Six individual homozygous mutant FAD2$1 \mathrm{~A}_{3}$ plants representing two independent $\mathrm{F}_{2}$ individuals and five individual homozygous wild-type FAD2-1A $\mathrm{F}_{3}$ plants representing two independent $\mathrm{F}_{2}$ individuals were germinated in germination packets and transferred to the field at BREC in 2008 for production of $\mathrm{F}_{4}$ seeds. Five seeds from each plant were sampled for individual fatty acid analysis.

\section{Population Screening}

Reverse genetics gene screening

A portion of RS2 was screened for EMS induced mutations. Exon 1 of RS2 was screened using IR 700 and IR 800 labeled primers: 5'-GAGTCTCATATTGTACATGGTAG-3' and 5'-GCAATTCGATGCTTCTTATGAG-3'. A portion of FAD2-1A was first amplified with unlabeled primers (to overcome poor amplification of DNA directly with the labeled primers) followed by amplification with IR 700 and IR 800 labeled primers: 5'GTAGAGGTCGTGTGGCCAAAGTGGAAG-3' and 5'AACCATGATCGCAACAAGCTGTTTCAC-3'. Standard TILLING PCR parameters were as follows: One cycle of $95^{\circ} \mathrm{C}$ for 2 minutes and $94^{\circ} \mathrm{C}$ for 20 seconds followed by 56 cycles of $94^{\circ} \mathrm{C}$ for 20 seconds, $56^{\circ} \mathrm{C}$ for 30 seconds, and $72^{\circ} \mathrm{C}$ for 1 minute. The next step in the PCR was $72^{\circ} \mathrm{C}$ for $5 \mathrm{~min}$ utes, then a $99^{\circ} \mathrm{C}$ step for 10 minutes followed by a $70^{\circ} \mathrm{C}$ to $0^{\circ} \mathrm{C}$ melt. The reactions were then held at $10^{\circ} \mathrm{C}$. Cel I based cleavage of PCR products and detection with polyacrylamide gels was essentially as described [2].

Pools containing cleaved products indicating an induced mutation or heteroduplex mismatch were deconvoluted by separating the pools into individual plant DNA samples for sequencing in order to identify the line containing the mutation [1-3]. The location of the mutation as well as the zygosity could then be verified. The RS2 mutations were confirmed by PCR amplification of a portion of the gene followed by sequence analysis. Primers used were $5^{\prime}$ CCCACCATGTCACCACACC-3' and 5'-GGTGATGAATTTTTAGCGGCG-3'. PCR parameters were $95^{\circ} \mathrm{C}$ for
10 minutes, followed by 35 cycles of $95^{\circ} \mathrm{C}$ for 30 seconds, $60^{\circ} \mathrm{C}$ for 30 seconds, and $72^{\circ} \mathrm{C}$ for 30 seconds, and then 5 minutes at $72^{\circ} \mathrm{C}$; the reaction was held at $4{ }^{\circ} \mathrm{C}$. Screening for the RS2 candidate gene was carried out at Purdue University in West Lafayette, IN and screening for the FAD2-1A candidate gene was carried out at the Fred Hutchinson Cancer Research Center.

\section{Allele-Specific Molecular Marker Assay Development RS2 allele-specific molecular marker assay}

An allele specific molecular marker assay was developed for the mutation identified in line 397 to discriminate between wild-type Williams 82 or mutant alleles of the RS2 gene. The assay was designed as described [34]. In order to achieve allele specificity, single base pair mismatches were introduced into the primer sequence to increase the discriminatory power of the allele-specific primer. These bases and the tails are indicated in lowercase in the primer sequences. Primer sequences were: $5^{\prime}-$ gcgggcGTTGCTACCGACCCAGtGAA-3', 5'-gcgggcagggcggcGTTGCTACCGAC CCAGcGAG-3', and a common forward primer 5'-CAGAGGAATAAAATTCATGAGCATA-3'.

Reactions were carried out in $20 \mu \mathrm{l}$; each primer was at 0.5 $\mu \mathrm{M}$ final concentration in reactions containing template, buffer (40 mM Tricine-KOH (pH 8.0), $16 \mathrm{mM} \mathrm{KCl,} 3.5$ $\mathrm{mM} \mathrm{MgCl} 2,3.75 \mu \mathrm{g} \mathrm{ml}-1$ BSA, $200 \mu \mathrm{M}$ dNTPs), 5\% DMSO, 0.25× SYBR Green I, and 0.2× Titanium Taq polymerase (BD Biosciences, Palo Alto, CA).

PCR parameters on a DNA Engine Opticon 2 (MJ Research/Bio-Rad, Hercules, California) for the RS2 assay were as follows: $95^{\circ} \mathrm{C}$ for 12 minutes followed by 35 cycles of $95^{\circ} \mathrm{C}$ for 20 seconds, $60^{\circ} \mathrm{C}$ for 30 seconds, $72^{\circ} \mathrm{C}$ for 30 seconds, and then a melting curve from $72^{\circ} \mathrm{C}$ to $90^{\circ} \mathrm{C}$. The fluorescence was read after each cycle and every $0.2^{\circ} \mathrm{C}$ with a one second hold during the melt. Each genotype produced a product with a characteristic melting profile, as measured by $\mathrm{T}_{\mathrm{m}}$ of the negative first derivative of the disappearance of fluorescent signal. The Williams 82 homozygous genotype gave a peak at $83.6^{\circ} \mathrm{C}$, mutant homozygous genotype gave a peak at $79.2^{\circ} \mathrm{C}$, and a heterozygous genotype gave a peak at $83.6^{\circ} \mathrm{C}$ with a shoulder at $79.0^{\circ} \mathrm{C}$. Templates for PCR were $1.2 \mathrm{~mm}$ washed FTA (Whatman, Clifton, NJ) card punches prepared from leaves according to the manufacturer's instructions

\section{FAD2-I A allele-specific molecular marker assay}

The TILLING screen originally identified line $18 \mathrm{D}$ as heterozygous for the S117N FAD2-1A mutation. Re-isolation of DNA from line $18 \mathrm{D}$ as well as line $16 \mathrm{D}$ and $17 \mathrm{D} \mathrm{M}_{2}$ tissue and FAD2-1A sequence characterization revealed that line $18 \mathrm{D}$ (or 16D) did not contain the variant allele of FAD2-1A, but line 17D was homozygous for the S117N mutation. FAD2-1A specific gene amplification and 
sequencing was performed with the primers: 5 '-accacctacttccacctccttcctcaa-3' and 5'-TATATGGGAGCATAAGGGTGGTAGTGGCTT-3'. The homozygous state of the S117N FAD2-1A allele in $\mathrm{M}_{3}$ seedlings from line $17 \mathrm{D}$ was also confirmed by sequencing.

An allele specific GC-tail molecular marker assay was developed for the S117N FAD2-1A allele identified in line 17D [34]. The primers used were: 5'-gcgggcagggcggcATCAACCCATTGGTACTTGC-3'; 5'-gcgccgATCAACCCATTGGTACTTGT-3'; and 5'-GTTGCCTTCTCACTGGTG-3'. Reactions were carried out in $15 \mu \mathrm{l}$; reaction conditions were the same as those in the RS2 allele-specific assay. PCR parameters on a DNA Engine Opticon 2 (MJ Research/Bio-Rad) for the FAD2-1A GC Tail assay were as follows: $95^{\circ} \mathrm{C}$ for 5 minutes followed by 35 cycles of $95^{\circ} \mathrm{C}$ for 20 seconds, $65^{\circ} \mathrm{C}$ for 20 seconds, $72^{\circ} \mathrm{C}$ for 20 seconds, and then a melting curve from $75^{\circ} \mathrm{C}$ to $85^{\circ} \mathrm{C}$. The fluorescence was read after each cycle and every $0.2^{\circ} \mathrm{C}$ with a one second hold during the melt with excitation at 470-505 $\mathrm{nm}$ and detection at 523-543 nm.. Each genotype produced a product with a characteristic melting profile, as measured by $\mathrm{T}_{\mathrm{m}}$ of the negative first derivative of the disappearance of fluorescent signal. Homozygous wild-type FAD2-1A alleles produced a peak at $83^{\circ} \mathrm{C}$, homozygous mutant alleles produced a peak at $81^{\circ} \mathrm{C}$, and heterozygous samples produced both peaks. Templates for PCR were either genomic DNA samples isolated using the DNeasy Plant Mini Kit (Qiagen, Inc., Valencia, CA) or $1.2 \mathrm{~mm}$ washed FTA (Whatman) card punches prepared from leaves according to the manufacturer's instructions.

\section{Oligosaccharide Phenotype Determination}

Oligosaccharides were determined by high performance ion chromatography with pulsed amperometric detection (PAD) employing an Agilent 1100 series HPLC and an ESA Coulochem III detector (Agilent Technologies, Chesterfield, MO, USA). A $12.5 \mathrm{mg}$ ground seed sample from either a whole seed or a chipped seed (seed were cut with a razor blade so that approximately $1 / 2$ could be used for oligosaccharide extract and the remaining half could be

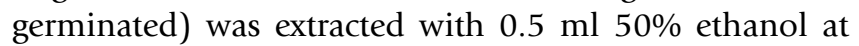
$70^{\circ} \mathrm{C}, 30 \mathrm{~min}$. Samples were then centrifuged $15 \mathrm{~min}$ at $16,000 \mathrm{~g}$. The supernatant was passed through a $0.2 \mu \mathrm{m}$ filter. Sugars were separated on a Dionex Carbo Pac PA 10 analytical column $(250 \mathrm{~mm} \times 4 \mathrm{~mm}, 10 \mu \mathrm{m})$ connected to a Carbo Pac PA 10 guard column $(50 \mathrm{~mm} \times 4 \mathrm{~mm})$. The mobile phase was $90 \mathrm{mM} \mathrm{NaOH}$ with flow rate of $1.5 \mathrm{ml}$ min $^{-1}$, maintained at $30^{\circ} \mathrm{C}$. Detection settings were: time $0,0.1 \mathrm{v}$, time $0.41,-2.0 \mathrm{v}$, time $0.42,0.6 \mathrm{v}$, and time 0.44 , $-0.1 \mathrm{v}$.

\section{Fatty Acid Phenotype Determination}

The fatty acid profiles of individual whole crushed seeds was determined by lipid gas chromatography of total fatty acid methyl esters of extracted oil, as previously described [33]. Five individual seeds from each of five plants were sampled from each line.

\section{Abbreviations}

TILLING: Targeting induced local lesions in genomes; RS: raffinose synthase; FAD: fatty-acid desaturase; EMS: ethylmethanesulfonate; NMU: N-nitroso-N-methylurea; SNP: single nucleotide polymorphism; PCR: polymerase chain reaction; NCBI: National Center for Biotechnology Information.

\section{Authors' contributions}

ED designed and performed the raffinose synthase experiments and co-authored the manuscript. KB designed and performed the fatty acid desaturase experiments, guided the raffinose synthase experiments, and co-authored the manuscript. Both authors approved the final manuscript.

\section{Acknowledgements}

The authors gratefully acknowledge the skilled technical assistance of Paul Little, Ashley Tetlow, and Christy Cole. TILLING screens were conducted by Jennifer Cooper and Steve Henikoff at the Seattle TILLING project and Rita Monde and Cliff Weil at the Maize TILLING project. Funding for this project was provided in part by the United Soybean Board, and the National Center for Soybean Biotechnology at the University of Missouri. Emily Dierking was supported by a University of Missouri Life Sciences Doctoral Fellowship.

\section{References}

I. McCallum CM, Comai L, Greene EA, Henikoff S: Targeting induced local lesions IN genomes (TILLING) for plant functional genomics. Plant Physiol 2000, I 23(2):439-442.

2. Colbert T, Till BJ, Tompa R, Reynolds S, Steine MN, Yeung AT, McCallum CM, Comai L, Henikoff S: High-throughput screening for induced point mutations. Plant Physiol 200 I, I 26(2):480-484.

3. McCallum CM, Comai L, Greene EA, Henikoff S: Targeted screening for induced mutations. Nature Biotechnology 2000, 18:455-457.

4. Cooper J, Till B, Laport R, Darlow M, Kleffner J, Jamai A, El-Mellouki T, Liu S, Ritchie R, Nielsen N, Bilyeu K, Meksem K, Comai L, Henikoff $S$ : TILLING to detect induced mutations in soybean. $B M C$ Plant Biology 2008, 8(I):9.

5. Olhoft P, Donovan C, Somers D: Soybean (Glycine max) tranformation using immature cotyledonary node explants. In Agrobacterium Protocols Volume 343. 2nd edition. Totowa, NJ: Humana Press; 1996:385-396.

6. Somers DA, Samac DA, Olhoft PM: Recent advances in legume transformation. Plant Physiol 2003, I 3 I (3):892-899.

7. Flores T, Karpova O, Su X, Zeng P, Bilyeu K, Sleper D, Nguyen $H$, Zhang Z: Silencing of Gm FAD3 gene by siRNA leads to low $\alpha$ linolenic acids (18:3) of fad3-mutant phenotype in soybean [Glycine max (Merr.)]. Transgenic Research 2008, I 7(5):839-850.

8. Li X-P, Gan R, Li P-L, Ma Y-Y, Zhang L-W, Zhang R, Wang Y, Wang $\mathrm{N}$ : Identification and functional characterization of a leucinerich repeat receptor-like kinase gene that is involved in regulation of soybean leaf senescence. Plant Molecular Biology 2006, 6I(6):829-844.

9. Subramanian S, Graham MY, Yu O, Graham TL: RNA interference of soybean isoflavone synthase genes leads to silencing in tissues distal to the transformation site and to enhanced susceptibility to Phytophthora sojae. Plant Physiol 2005, I37(4): 1345-1353.

10. Buhr T, Sato S, Aiqiu FE, Zhou XY, Mathiesen M, Schweiger B, Kinney A, Staswick P: Ribozyme termination of RNA transcripts 
down-regulate seed fatty acid genes in transgenic soybean. The Plant Journal 2002, 30(2): 155-163.

II. Schlueter JA, Lin JY, Schlueter SD, Vasylenko-Sanders IF, Deshpande $\mathrm{S}$, Yi J, O'Bleness M, Roe BA, Nelson RT, Scheffler BE, Jackson SA, Shoemaker RC: Gene duplication and paleopolyploidy in soybean and the implications for whole genome sequencing. BMC genomics 2007, 8:330.

12. Shoemaker RC, Polzin K, Labate J, Specht J, Brummer EC, Olson T, Young N, Concibido V, Wilcox J, Tamulonis JP, Kochert G, Boerma HR: Genome duplication in soybean (Glycine subgenus soja). Genetics 1996, I44(I):329-338.

13. Shoemaker RC, Schlueter J, Doyle J]: Paleopolyploidy and gene duplication in soybean and other legumes. Current opinion in plant biology 2006, 9(2): 104-109.

14. Bilyeu KD, Palavalli L, Sleper DA, Beuselinck PR: Three microsomal omega-3 fatty-acid desaturase genes contribute to soybean linolenic acid levels. Crop Science 2003, 43(5): $1833-1838$.

15. Gillman J, Pantalone V, Bilyeu K: The low phytic acid phenotype in soybean line CXI834 is due to mutations in two homologs of the maize low phytic acid gene. The Plant Genome 2009, 2(2): $179-190$.

16. Dierking EC, Bilyeu KD: Association of a soybean raffinose synthase gene with low raffinose and stachyose seed phenotype. The Plant Genome 2008, I(2): I35- I 45.

17. Okuley J, Lightner J, Feldmann K, Yadav N, Lark E, Browse J: ArabidopsIS FAD2 gene encodes the enzyme that is essential for polyunsaturated lipid synthesis. Plant Cell 1994, 6(I): I47-I58.

18. Alt JL, Fehr WR, Welke GA, Sandhu D: Phenotypic and molecular analysis of oleate content in the mutant soybean line M23. Crop Sci 2005, 45(5): 1997-2000

19. Anai T, Yamada T, Hideshima R, Kinoshita T, Rahman SM, Takagi Y: Two high-oleic-acid soybean mutants, M23 and KK2I, have disrupted microsomal omega-6 fatty acid desaturase, encoded by GmFAD2-IA. Breeding Science 2008, 58(4):447-452.

20. Rahman SM, Kinoshita T, Anai T, Takagi Y: Combining ability in loci for high oleic and low linolenic acids in soybean. Crop Sc 200I, 4 I (I):26-29.

21. Graef G, LaVallee BJ, Tenopir P, Tat M, Schweiger B, Kinney AJ, Gerpen JHV, Clemente TE: A high-oleic-acid and low-palmitic-acid soybean: agronomic performance and evaluation as a feedstock for biodiesel. Plant Biotechnology Journal 2009, 7(5):4I I-42 I.

22. Oliva ML, Shannon JG, Sleper DA, Ellersieck MR, Cardinal AJ, Paris $R L$, Lee JD: Stability of fatty acid profile in soybean genotypes with modified seed oil composition. Crop Sci 2006 46(5):2069-2075.

23. Crooks GE, Hon G, Chandonia J-M, Brenner SE: WebLogo: A sequence logo generator. Genome Research 2004, 14(6): $1188-1190$.

24. Shanklin J, Whittle E, Fox BG: Eight histidine residues are catalytically essential in a membrane-associated iron enzyme, stearoyl-CoA desaturase, and are conserved in alkane hydroxylase and xylene monooxygenase. Biochemistry 1994, 33(43): 12787-12794.

25. Bernard RL, Cremeens CR: Registration of 'Williams 82' Soybean. Crop Sci 1988, 28(6): 1027-1028.

26. Tang G-Q, Novitzky WP, Griffin HC, Huber SC, Dewey RE: Oleate desaturase enzymes of soybean: evidence of regulation through differential stability and phosphorylation. The Plant Journal 2005, 44(3):433-446.

27. Byfield GE, Upchurch RG: Effect of temperature on delta-9 stearoyl-ACP and microsomal omega-6 desaturase gene expression and fatty acid content in developing soybean seeds. Crop Sci 2007, 47(4): 1698-1704.

28. Schlueter JA, Vasylenko-Sanders IF, Deshpande S, Yi J, Siegfried M, Roe BA, Schlueter SD, Scheffler BE, Shoemaker RC: The FAD2 gene family of soybean:: Insights into the structural and functional divergence of a paleopolyploid genome. Crop Sci 2007, 47(Supplement_I):S-14-26.

29. Triques K, Sturbois B, Gallais S, Dalmais M, Chauvin S, Clepet C Aubourg S, Rameau C, Caboche M, Bendahmane A: Characterization of Arabidopsis thaliana mismatch specific endonucleases: application to mutation discovery by TILLING in pea. The Plant Journal 2007, 5 I (6): I I I6-I I 25.

30. Xin Z, Li Wang M, Barkley N, Burow G, Franks C, Pederson G, Burke $\mathrm{J}$ : Applying genotyping (TILLING) and phenotyping analyses to elucidate gene function in a chemically induced sorghum mutant population. BMC Plant Biology 2008, 8(I): 103.

31. Dong C, Dalton-Morgan J, Vincent K, Sharp P: A modified TILLING method for wheat breeding. The Plant Genome 2009, 2(1):39-47.

32. Wang N, Wang Y, Tian F, King G], Zhang C, Long Y, Shi L, Meng J: A functional genomics resource for Brassica napus: development of an EMS mutagenized population and discovery of FAEI point mutations by TILLING. New Phytologist 2008, I 80(4):75।-765.

33. Bilyeu K, Palavalli L, Sleper D, Beuselinck P: Mutations in soybean microsomal omega-3 fatty acid desaturase genes reduce linolenic acid concentration in soybean seeds. Crop Sci 2005, 45(5): $1830-1836$

34. Wang J, Chuang K, Ahluwalia M, Patel S, Umblas N, Mirel D, Higuchi $R$, Germer S: High-throughput SNP genotyping by single-tube PCR with Tm-shift primers. Biotechniques 2005, 39(6):885-893.

Publish with Bio Med Central and every scientist can read your work free of charge

"BioMed Central will be the most significant development for disseminating the results of biomedical research in our lifetime. "

Sir Paul Nurse, Cancer Research UK

Your research papers will be:

- available free of charge to the entire biomedical community

- peer reviewed and published immediately upon acceptance

- cited in PubMed and archived on PubMed Central

- yours - you keep the copyright 